\title{
PARADIGMAS Y FUNDAMENTOS DE LA CONFLICTIVA RELACIÓN ENTRE LA COMISIÓN DE ARQUITECTURA Y LA CIUDAD DE SEVILLA (1786-1808)
}

\author{
PARADIGMS AND FOUNDATIONS OF THE \\ CONFLICTIVE RELATIONSHIP BETWEEN \\ THE COMMISSION OF ARCHITECTURE \\ AND THE CITY OF SEVILLE (1786-1808)
}

\author{
Jesús María Ruiz CARRAsco \\ Universidad de Córdoba. España \\ 192rucaj@uco.es
}

\begin{abstract}
A partir de la publicación del Real Decreto de 1777 y la fundación de la Comisión de Arquitectura en 1786, la Real Academia de San Fernando adquirió la facultad y los instrumentos necesarios para examinar los proyectos constructivos delineados a lo largo y ancho del territorio nacional. No obstante, la entrada en vigor de dichas órdenes y la labor de los comisionados académicos no obtuvo los mismos resultados en todos los reinos que conformaban la corona española, siendo el de Sevilla uno de los más reacios a aceptar la nueva normativa. Una oposición al proceso introductorio de los preceptos academicistas en la arquitectura de la ciudad hispalense cuyas razones, circunstancias y ejemplos centran este artículo.

Palabras clave: Sevilla; Academia; Comisión de Arquitectura; académico; arquitecto.
\end{abstract}

As of the publication of the Royal Decree of 1777 and the founding of the Commission of Architecture in 1786, the Royal Academy of San Fernando gained the faculty and the required resources to examine the structural projects delineated far and wide of the national territory. However, the implementation of these orders and the work of the academic commissioners didn't get the same results in all of the kingdoms that integrated the Spanish Crown, being the Kingdom of Seville one of the most reluctant to accept the new regulations. One opposition to the introductory process of the academic precepts in the architecture of the City of Seville whose reasons, circumstances and examples focus this paper.

Keywords: Seville; Academy; Commission of Architecture; academic; architect. 
Con la promulgación del Real Decreto refrendado por la Corona el 23 de noviembre de $1777^{1}$, la Real Academia de Bellas Artes de San Fernando obtuvo facultad para examinar y modificar todas las obras públicas proyectadas en el territorio nacional. Esta resolución, que legitimó el afán intervencionista de los académicos, derivó de una súplica dirigida a la Corona el 23 de agosto del mismo año y redactada por la junta de consiliarios de la Academia, titulada "Consulta al rey sobre la arquitectura de los Templos"2. No obstante, la citada orden no tuvo el efecto deseado por parte de sus promotores, tanto por la desatención que determinadas instituciones mostraron ante la nueva normativa, como por la sobrecarga que sufría la junta ordinaria de la Academia, incapaz de evaluar la totalidad de los diseños que se le presentaban ${ }^{3}$. Dichas dificultades motivaron que ciertos académicos, entre los que destacó Antonio Ponz ${ }^{4}$, promovieran la creación de un organismo específico capacitado para supervisar los proyectos arquitectónicos enviados a la Academia: la Comisión de Arquitectura, instituida el 22 de marzo de $1786^{5}$. Una fundación que tuvo consecuencias inmediatas, puesto que examinó 973 proyectos desde el año de su fundación hasta $1790^{6}, 731$ entre $1790 \mathrm{y}$ $1793^{7}$, y 393 desde 1793 hasta $1796^{8}$. No obstante, y a pesar de estas cifras tan significativas, la labor divulgativa de los preceptos arquitectónicos promovidos por

${ }^{1}$ El contenido y el proceso de tramitación del Real Decreto aparece contenido en ESCOLANO DE ARRIETA, Pedro: Práctica del Consejo Real en el despacho de los negocios consultivos, instructivos y contenciosos: con distinción de los que pertenecen al consejo pleno, ó á cada sala particular: y las fórmulas de las cédulas, provisiones y certificaciones respectivas. T. II. Madrid, 1796, pp. 19-24.

${ }^{2}$ Carta recogida en su totalidad en la junta particular de la Academia celebrada el 10 de agosto de 1777. ARABASF (Archivo de la Real Academia de Bellas Artes de San Fernando), Libros de actas de las sesiones particulares y de gobierno, leg. 3/123, ff. 78v-86r.

${ }^{3}$ La creciente llegada de proyectos constructivos a la junta ordinaria de la Academia a partir de 1777 prolongaba en demasía las sesiones de la misma, que también debía de hacerse cargo de otras muchas cuestiones referentes al funcionamiento del organismo. Véase MARTÍN GONZÁLEZ, Juan José: "Problemática del retablo bajo Carlos III", Fragmentos, 12-14, 1988, pp. 32-43.

${ }^{4}$ Cuya decisiva participación quedó reflejada en Distribución de los premios concedidos por el rey nuestro señor à los discípulos de las tres nobles artes, hecha por la Real Academia de San Fernando en la Junta pública de 20 de agosto de 1793. Madrid, 1793, pp. 28-29.

${ }^{5}$ Mediante una Real Cédula firmada en el Palacio del Pardo en la fecha indicada, y recogida en la junta ordinaria de la Academia del 2 de abril de 1786. ARABASF, Libros de actas de las sesiones particulares, ordinarias, generales, extraordinarias, públicas y solemnes, leg. 3/85, ff. 7r-11r.

${ }_{6}$ Junta ordinaria del 3 de julio de 1791. Ibidem, f. 163 r.

7 Distribución de los premios... 1793, op. cit., p. 12.

8 Distribución de los premios concedidos por el rey nuestro señor á los discípulos de las tres nobles artes, hecha por la Real Academia de San Fernando en la Junta pública de 13 de Julio de 1796. Madrid, 1796, p. 20. 
la Academia no dio resultado en determinados municipios. Este fue el caso de Sevilla, donde la actividad reguladora de la Comisión de Arquitectura resultó infructífera a causa de una serie de factores cuya exposición y análisis centran este artículo.

La capital hispalense, en la que trabajaron una serie de ingenieros militares a instancias de la Corona durante el siglo XVIII, congregó a figuras destacadas de la Ilustración española que impulsaron los ideales de este movimiento cultural durante el último tercio de la citada centuria ${ }^{9}$. Como consecuencia de este ambiente, los emergentes círculos artísticos relacionados con este espíritu de renovación originaron la fundación de la Real Escuela de las Tres Nobles Artes, reconocida oficialmente en $1775^{10}$. Esta institución, autorizada por la Corona y amparada por Francisco de Bruna, siguió inicialmente el ejemplo de las Reales Academias de Bellas Artes de San Fernando de Madrid y de San Carlos de Valencia en lo referente a estructura interna e ideales fundacionales ${ }^{11}$. Paralelamente, y como antecedente de la labor llevada a cabo por la Comisión de Arquitectura, cabe reseñar el reconocimiento de la iglesia del Sagrario de la catedral de Sevilla llevado a cabo en 1778 por los arquitectos cortesanos Francisco Sabatini y Miguel Fernández, que derivó en la consecuente restauración del edificio. Fue una actuación promovida por el cabildo catedralicio y la Corona como consecuencia de las inoperantes propuestas presentadas en 1776 y 1777 por un grupo de arquitectos locales y foráneos con el objetivo de subsanar los supuestos problemas estructurales del citado templo ${ }^{12}$. Esta situación no solo escenificó por primera vez la disyuntiva existente entre los arquitectos académicos y los del ámbito hispalense, sino que también les reveló a estos últimos la competencia que debían afrontar si aspiraban a ser los adjudicatarios de los proyectos más relevantes de la ciudad. Una disputa que los artífices sevillanos no rehuyeron en ninguno de los casos.

Pese a los antecedentes, al contexto y a la fundación de la Comisión de Arquitectura en 1786, no fue hasta 1790 cuando dicho organismo evaluó el primero de los proyectos para la ciudad de Sevilla: el conjunto de la sillería y el facistol de la

${ }^{9}$ A dichos personajes, entre los que destacan Ponz, Jovellanos, Olavide, Ceán Bermúdez y Francisco de Bruna, se hace referencia en OLLERO LOBATO, Francisco: $\mathrm{Cul}$ tura Artística y Arquitectura en la Sevilla de la Ilustración (1775-1808). Sevilla, 2004, pp. $38-42$ y $49-73$

10 OLLERO LOBATO, Francisco: "La Ilustración en Sevilla: tradición y novedad en la arquitectura del siglo XVIII", en El Arte español en épocas de Transición. Actas del IX Congreso Nacional de Historia del Arte. Madrid, 1994, pp. 115-126.

${ }^{11}$ OLLERO LOBATO, Francisco: Cultura Artística y Arquitectura..., op. cit., pp. 75 111.

12 BRAVO BERNAL, Ana Mi: El Sagrario, un problema y su historia. Estudio arquitectónico y documental de la Capilla del Sagrario de la Catedral de Sevilla. Sevilla, 2008, pp. 137-163; y FALCÓN MÁRQUEZ, Teodoro: El Sagrario de la Catedral de Sevilla. Sevilla, 1977, pp. 78-83. 
Capilla Real ${ }^{13}$. Su realización, motivada por la necesidad de renovar el mobiliario de la capilla, fue amparada por Carlos IV tras una súplica de los capellanes, que eligieron en primera instancia los diseños realizados por el ebanista francés Pedro Corpel en febrero de $1790^{14}$. El proyecto fue remitido a la Comisión, que lo rechazó por "su gusto mezquino y propio de ebanista" en la junta celebrada el 30 de marzo del citado año ${ }^{15}$, durante la que también se propuso a Antonio Fernández Bertoni o a Mateo Medina para la realización de nuevos diseños para el citado conjunto ${ }^{16}$. Finalmente, fue Fernández Bertoni quien llevó a cabo "cuatro dibujos" para la "sillería, facistol y otros adornos de la Capilla Real de San Fernando", aprobados por la Comisión de Arquitectura el 12 de Junio de 1790, fecha en la que dicho organismo estimó en 25 doblones el pago por la ejecución de los diseños de Bertoni ${ }^{17}$, que se llevaron a la realidad entre el verano de 1790 y la primavera de $1791^{18}$. El resultado es una obra prototípica del ideal arquitectónico impulsado por la monarquía española, en el que la sencillez formal derivaba de la búsqueda del raciocinio, la solidez y el ahorro de caudales públicos ${ }^{19}$. Se trata de unas pautas que, por diferentes circunstancias, no proliferaron en la ciudad de Sevilla, donde la única obra ejecutada a partir de un proyecto aprobado por la Comisión de Arquitectura entre 1786 y 1808 fue el referido conjunto de la Capi1la Real.

El 23 de abril de 1790, escasos días después de que la Academia desestimase los diseños de Corpel para la sillería de la Capilla Real hispalense, la Comisión

${ }^{13}$ Dicho conjunto venía a completar la arquitectura de la Capilla Real, a la que durante la centuria que nos ocupa le fue añadida la reja que la precede, ideada por el ingeniero bruselense Sebastian van der Borcht. Sobre la citada reja véase MORALES, Alfredo J.: "Artes aplicadas e industriales en la Catedral de Sevilla", en La Catedral de Sevilla. Sevi1la, 1986, p. 567; GÁMEZ CASADO, Manuel: "El ingeniero Sebastián Van der Borcht en la Capilla Real de Sevilla", en ALBERO MUÑOZ, María del Mar y PÉREZ SÁNCHEZ, Manuel (eds.): Las artes de un espacio y un tiempo: el setecientos borbónico. Madrid, 2015, pp. 325-343; y GÁMEZ, Manuel: "Sobre la reja de la Capilla Real", Archivo Hispalense, 297-299, 2015, pp. 397-408.

${ }^{14}$ RECIO MIR, Álvaro: "Per me reges regnant. Carlos IV y María Luisa de Parma en la Capilla Real de Sevilla: patronato regio, academia y neoclasicismo", Reales Sitios, 165,2005 , p. 31.

${ }^{15}$ Igualmente la Comisión se refiere al citado ebanista como "Pedro Luis Corpel". ARABASF, Libros de actas de las sesiones celebradas por la Comisión/Sección de Arquitectura, leg. 3/139, f. 139r.

${ }^{16}$ Ibidem, f. 139v.

17 Ibid., f. $143 \mathrm{v}$.

${ }^{18}$ RECIO MIR, Álvaro: "Per me reges regnant...”, op. cit., p. 31.

19 GARCÍA MELERO, José Enrique: "Orígenes del control de los proyectos de obras públicas por la Academia de San Fernando (1768-1777)”, Espacio, tiempo y forma. Serie VII, Historia del arte, 11, 1998, pp. 287-342. 
de Arquitectura manifestó su parecer ante una singular propuesta remitida desde el arzobispado de Sevilla. Concretamente, fueron enviados a la Comisión cuatro borradores de retablos ejecutados por encargo del prelado Alonso Marcos de Llanes Argüelles, con el objetivo de servir de modelo para ulteriores proyectos retablísticos de la diócesis ${ }^{20}$. Aunque la disposición de los diseños les "pareció arreglada" a los comisionados académicos, estos rechazaron la iniciativa del arzobispado por considerar inoportuno "querer sujetar los altares nuevos a plantillas determinadas" 21 . Esta decisión implicaba aparentemente una contradicción en el ideario de los propios académicos, pues la toma en consideración de la propuesta remitida por la prelatura hispalense hubiera fomentado la unificación de criterios estéticos divulgada por la Academia ${ }^{22}$. Sin embargo, la razón principal que motivó el rechazo de la iniciativa arzobispal fue la desconfianza que los académicos profesaban hacia las futuras ejecuciones de los retablos, ya que la Comisión estimaba que de aprobarse la propuesta, las obras derivadas de la misma padecerían "defectos enormes y barbaridades" provocados "por las alteraciones que se harían en sus medidas" 23 .

La conjunción de la armonía, el decoro, la unidad ${ }^{24}$ y la adecuación de los retablos a su correspondiente marco arquitectónico constituía una de las mayores preocupaciones de los miembros de la Comisión. No obstante, el rechazo de la propuesta del arzobispado llevaba implícita una crítica de los académicos al trabajo de los artífices sevillanos. En el caso de que la dirección de tales proyectos hubiera recaído en un arquitecto académico, la Comisión de Arquitectura hubiera recomendado ciertas medidas no imperativas para adecuar los diseños a su lugar de destino, dejando su aplicación en manos del arquitecto en cuestión,

${ }^{20}$ ROS GONZÁLEZ, Francisco S.: "Los modelos de retablos de arzobispo sevillano Alonso Marcos de Llanes y Argüelles”, en PANIAGUA PÉREZ, Jesús (coord.): España y América entre el Barroco y la Ilustración (1722-1804). II Centenario de la muerte del Cardenal Lorenzana (1804-2004). León, 2005, pp. 591-605.

${ }^{21}$ ARABASF, Libros de actas de las sesiones celebradas por la Comisión/Sección de Arquitectura, leg. 3/139, f. 140r.

${ }^{22}$ Incluso, en referencia al tema que nos ocupa se ha determinado que "la imitación era uno de los principios fundamentales del credo académico". ROS GONZÁLEZ, Francisco S.: "Los modelos de retablos...", op. cit., p. 594.

${ }^{23}$ ARABASF, Libros de actas de las sesiones celebradas por la Comisión/Sección de Arquitectura, leg. 3/139, f. 140r.

${ }^{24}$ Términos destacados de cuantos conformaban el lenguaje académico, así como virtudes esenciales que debían percibir los miembros de la Comisión de Arquitectura en cualquier proyecto cuya aprobación por parte de este organismo fuera deseada. Los términos aparecen acertadamente expuestos en GARCÍA MELERO, José Enrique: "Las cárceles españolas de la Ilustración y su censura en la Academia (1777-1808)", Espacio, tiempo y forma. Serie VII, Historia del arte, 8, 1995, p. 271. 
como testimonian otros ejemplos contenidos en la actas de dicho organismo ${ }^{25}$. Esto también evidencia que los diseños que nos ocupan no fueron delineados por ningún arquitecto formado en la Academia, pues de ser así las actas de la Comisión de Arquitectura hubieran reflejado la autoría de los mismos, dada la importancia que la institución académica otorgaba a la proyección de obras como parte de la actividad intelectual de sus miembros. Erudición, basada en la creencia y la interpretación ${ }^{26}$ de una serie de preceptos inmutables y universales, de la que hacía gala la Academia como contraposición al pragmatismo carente de toda reflexión teórica que este organismo imputaba a los maestros alarifes ${ }^{27}$, quienes a su vez acusaban a la Academia de idear proyectos arquitectónicos en base a la mera imitación formal. Por ello, no es de extrañar la decisión académica ante la propuesta de la prelatura hispalense, que además evitó la tergiversación de un proyecto que concordaba con el lenguaje arquitectónico oficial del Estado. Tales desfiguraciones formales, a causa de la labor taimada de los artífices locales, sí afectaron a otros proyectos aprobados por la Comisión de Arquitectura para la ciudad de Sevilla.

Es sabido que, al menos, uno de los cuatro diseños retablísticos propuestos por la prelatura hispalense y rechazados por la Comisión de Arquitectura se intentó llevar a cabo en madera con el consentimiento del arzobispo Llanes Argüe$1 l e{ }^{28}$. Esta decisión no solo evidenciaba la desatención de ciertas instituciones eclesiásticas a los dictámenes de la Academia, sino también el desacato de las mismas ante la circular firmada por el conde de Floridablanca el 23 de noviembre de 1777, enviada a obispos y arzobispos con motivo del Real Decreto promulgado en esa misma fecha ${ }^{29}$. La misma, centrada en prevenir a los prelados españoles sobre los beneficios implícitos en la excusación del empleo de madera para la composición de retablos, contó con una aceptación limitada que provocó su instancia

${ }^{25}$ Citamos como ejemplo las modificaciones que la Comisión de Arquitectura recomendó a Ignacio Tomás para mejorar el proyecto de la iglesia de Santa Bárbara de Écija en la junta celebrada el 1 de diciembre de 1790. Recomendaciones que no fueron aplicadas por el arquitecto académico. ARABASF, Libros de actas de las sesiones celebradas por la Comisión/Sección de Arquitectura, leg. 3/139, ff. 152v-153r.

${ }^{26}$ Recordemos los conflictos teórico-prácticos en los que, ya en la década de 1750, algunos académicos se vieron implicados, destacando entre ellos el protagonizado por Diego de Villanueva y Ventura Rodríguez. SAMBRICIO, Carlos: "José de Hermosilla y el ideal historicista en la arquitectura de la Ilustración”, Goya, 159, 1980, p. 147.

${ }^{27}$ GARCÍA MELERO, José Enrique: "El arquitecto académico a finales del siglo XVIII”, Espacio, tiempo y forma. Serie VII, Historia del arte, 10, 1997, pp. 161-216.

${ }^{28}$ ROS GONZÁLEZ, Francisco S.: "Los modelos de retablos...”, op. cit., pp. 594596.

${ }^{29} \mathrm{Su}$ contenido íntegro aparece reflejado en la junta particular de la Real Academia de Bellas Artes de San Fernando fechada el 29 de noviembre de 1777. ARABASF, Libros de actas de las sesiones particulares y de gobierno, leg- 3/123, ff. 99r-101r. 
en diversas ocasiones, hasta la difusión de otra carta firmada el 8 de noviembre de 1791 por el conde de Floridablanca y el arzobispo de Toledo con motivo de una nueva Real Orden que vedaba la ejecución de retablos lignarios ${ }^{30}$. El carácter prohibitorio de esta medida restringió significativamente la inclusión del dorado y de adornos excesivos en los nuevos retablos ejecutados a lo largo y ancho del territorio estatal. Sin embargo, el cumplimiento de este decreto causó problemas de gran magnitud a los comitentes hispalenses, que debían acatar la nueva normativa pese al desconocimiento de los artífices locales de las técnicas necesarias para materializar altares pétreos.

El primer proyecto arquitectónico abordado en Sevilla tras la promulgación de la citada prohibición fue el correspondiente al nuevo retablo mayor de la parroquia de Ominum Sanctorum, cuyo proceso de adjudicación provocó una de las lides más intrincadas de la historia de la arquitectura hispalense. Atendiendo al deficiente estado de conservación del primigenio retablo mayor de la mencionada parroquia, Miguel de la Cueva, duque de Alburquerque y patrono de la capilla mayor del templo, tomó la decisión de reparar o reedificar dicho altar "hacia $1790 " 31$. La iniciativa del duque atrajo la participación de Manuel Barrera y Carmona $^{32}$, Dionisio José Gutierrez, José González Cardoso y José Gabriel Gonzá$1 \mathrm{ez}{ }^{33}$, quienes presentaron diferentes propuestas de reparación del antiguo retablo y de construcción de uno nuevo durante el verano de $1791^{34}$. Dichos proyectos fueron enviados para su evaluación el 29 de febrero de 1792 a la Comisión de Arquitectura, que calificó como "inaprobables" todos los planos formados por "distintos sujetos con el fin de reformar y adicionar" el retablo mayor de la parroquia de Omnium Sanctorum ${ }^{35}$. Asimismo, la Comisión, que recalcó las deficiencias contenidas en los planes presentados por los artífices sevillanos, dictaminó que el

${ }^{30}$ Véase el contenido de la junta ordinaria de la Academia celebrada el 18 de diciembre de 1791. ARABASF, Libros de actas de las sesiones particulares, ordinarias, generales, extraordinarias, públicas y solemnes, leg. 3/85, ff. 183v-184r.

${ }^{31}$ ROS GONZÁLEZ, Francisco S.: "El retablo mayor de estuco de la parroquia de Omnium Sanctorum de Sevilla (1791-1793)", Laboratorio de Arte, 13, 2000, p. 55.

${ }^{32}$ Sobre este maestro tallista consúltese RODA PEÑA, José: "Manuel Barrera y Carmona, retablista en la Sevilla de Carlos III", Archivo Hispalense, 217, 1988, pp. 197-222.

${ }_{33}$ Diferentes datos biográficos sobre Manuel Barrera Carmona y José Gabriel González, así como sobre otros maestros tallistas de las dos últimas décadas del siglo XVIII, aparecen contenidos en ROS GONZÁLEZ, Francisco S.: Noticias de escultura (17811800 ). Sevilla, 1999.

${ }^{34}$ La participación de los citados artífices viene contenida en FERNÁNDEZ GONZÁLEZ, Alberto: "Trazas y proyectos para el desaparecido retablo mayor de estuco de la iglesia parroquial de Omnium Sanctorum de Sevilla", Laboratorio de Arte, 20, 2007, pp. 204-206.

35 ARABASF, Libros de actas de las sesiones celebradas por la Comisión/Sección de Arquitectura, leg. 3/139, f. 184v. 
patrono de la obra debía encargar "un diseño arreglado" para esta a un "profesor de reconocido mérito", previo informe de su ubicación y de los caudales destinados a su construcción, que "en conformidad con las Reales Órdenes" debía de realizarse en estuco ${ }^{36}$. Además de señalar que los proyectos para el citado retablo se presentaron con anterioridad a la promulgación de la normativa de noviembre de 1791, cabe destacar la displicencia usual con la que los miembros de la Comisión trataron a los proyectistas de la obra que nos ocupa. Esta misma incomprensión, aunque algo más suavizada, fue adoptada por el ingeniero militar Miguel de Hermosilla cuando el patrono de la obra le encargó la inspección de los proyectos enviados a la Academia y le pidió la elaboración de su propia idea para la ejecución del retablo ${ }^{37}$.

Hermosilla $^{38}$, que realizó también un segundo diseño el 30 de noviembre de 1792, tuvo que atender las exigencias del patrono de la obra, quien exhortó al citado ingeniero a incorporar una serie de imágenes al retablo y un camarín en su presidencia para albergar la talla de Nuestra Señora Reina de Todos los Santos $^{39}$. Dichas demandas propiciaron un marcado exceso ornamental en los diseños de Hermosilla en sus intentos por congeniar la "Nueva Arquitectura" con la incorporación de las mencionadas imágenes ${ }^{40}$. Estos proyectos evidencian la incompatibilidad entre las exigencias del patrono de la obra y los preceptos arquitectónicos impulsados por la Real Academia de San Fernando, que encontró en las cofradías otro sector hostil a su labor reformista de las artes. Esta circunstancia quedó certificada con la ejecución de un nuevo proyecto realizado por el destacado académico Carlos Vargas Machuca ${ }^{41}$ en abril de 1793, que a pesar de corresponder plenamente con la estética academicista, obvió las exigencias del patrono de la obra en lo referente a las imágenes que la debían completar y al camarín de la Virgen de Todos los Santos ${ }^{42}$. No obstante, lo verdaderamente relevante

36 Ibidem.

37 FERNÁNDEZ GONZÁLEZ, Alberto: “Trazas y proyectos...”, op. cit., pp. 206207.

${ }^{38}$ Sus datos biográficos aparecen contenidos en AA.VV.: Los ingenieros militares en españa siglo XVIII. Repertorio biográfico e inventario de su labor científica y espacial. Barcelona, 1983, pp. 223-226.

${ }^{39}$ FERNÁNDEZ GONZÁLEZ, Alberto: “Trazas y proyectos...”, op. cit., pp. 203-228.

40 Ambos proyectos pueden observarse en FERNÁNDEZ GONZÁLEZ, Alberto: “Trazas y proyectos...", op. cit., pp. 223-224.

${ }^{41}$ Fue discípulo de Juan Pedro Arnal, además de seguidor de sus conceptos más puramente clasicistas y destacado teórico e impulsor de los nuevos ideales arquitectónicos de la Academia en los albores del siglo XVIII. SAMBRICIO, Carlos: La Arquitectura española de la Ilustración. Madrid, 1986, pp. 88, 102, 187 y 287.

${ }^{42}$ Sobre el proyecto del retablo véase FERNÁNDEZ GONZÁLEZ, Alberto: "Trazas y proyectos...”, op. cit., p. 225. Otras informaciones aparecen contenidas en ROS GONZÁLEZ, Francisco S.: "El retablo mayor de estuco...”, op. cit., pp. 159-161. 
de las circunstancias que rodearon el proyecto de Vargas Machuca fue que él mismo aseguró, en una carta enviada al apoderado del duque de Alburquerque el 17 de abril de $1793^{43}$, que sus diseños para la realización del retablo mayor de la parroquia de Omnium Sanctorum habían sido aprobados por la Academia madrileña, cuando su examen no consta en las actas de dicho organismo. Se puede asegurar casi con toda seguridad que Vargas Machuca incurrió en una mentira para respaldar su propuesta ante el duque de Alburquerque y la Cofradía de la Virgen de Todos los Santos, que rechazaron el proyecto en un momento de apuros económicos del mencionado arquitecto ${ }^{44}$, circunstancia última que respalda la hipótesis sobre su más que supuesto engaño. Nuevamente, la actividad de los académicos y sus antagónicos en la ciudad de Sevilla propiciaron situaciones insólitas pero paradigmáticas de las dificultades implícitas en el proceso de difusión de los valores estéticos academicistas. En este caso, se puede apreciar la irregularidad cometida por un académico como consecuencia de las dificultades para conseguir la concesión de un proyecto en una situación difícil para él mismo, sabedor de la indefensión que sufrían los de su condición a causa de la desmaña con la que operaba la Academia en las provincias españolas ${ }^{45}$.

A pesar de todo, el episodio protagonizado por Vargas Machuca no fue el último relacionado con la disputa por la concesión del retablo mayor de la parroquia de Omnium Sanctorum. Paralelamente, el académico Juan Antonio Cuervo, teniente director de Arquitectura de la Academia a partir de 1801 y director de la misma rama desde $1814^{46}$, remitió a la Comisión de Arquitectura dos diseños de planta y alzado para la realización de la misma obra en estuco que fueron denegados en la junta del 8 de marzo de 1793 por "varios defectos sustanciales que hacían indispensable la formación de otros más arreglados" $"$. Seguidamente, la Comisión dictaminó que Cuervo se presentara personalmente en la Academia madrileña antes de ejecutar un nuevo proyecto, a fin de atender a las explicaciones de Manuel Martín Rodriguez ${ }^{48}$, quien le orientaría en representación de los

${ }^{43}$ Cuyo contenido aparece en FERNÁNDEZ GONZÁLEZ, Alberto: "Trazas y proyectos...", op. cit., pp. 216-218.

${ }^{44}$ Esto ya fue advertido en ROS GONZÁLEZ, Francisco S.: "El retablo mayor de estuco...", op. cit., p. 160.

45 Véase GARCÍA MELERO, José Enrique: "Arquitectura y burocracia: el proceso del proyecto en la Comisión de Arquitectura de la Academia (1786-1808)", Espacio, tiempo y forma. Serie VII, Historia del Arte, 4, 1991, pp. 283-348.

${ }^{46}$ Distribución de los premios concedidos por el rey nuestro señor á los discípulos de las tres nobles artes, hecha por la Real Academia de San Fernando en la Junta pública de 23 de Septiembre de 1808. Madrid, 1832, p. 230.

${ }^{47}$ ARABASF, Libros de actas de las sesiones celebradas por la Comisión/Sección de Arquitectura, leg. 3/139, f. 217r.

${ }^{48}$ Sobre el mismo véase CARDIÑANOS BARDECI, Inocencio: "El arquitecto Manuel Martín Rodríguez, discípulo de Ventura Rodríguez”, Academia, 71, 1990, pp. 411-480; 
comisionados ${ }^{49}$. Si bien la decisión de la Academia -que atendió a la "urgencia de la obra" - propició la aprobación del segundo diseño de Cuervo en la junta del 13 de abril de $1793^{50}$, significó en primera instancia la desacreditación de uno de sus miembros, ejemplificando así el oprobio al que se veían expuestos los académicos distribuidos por las diferentes provincias. Los esfuerzos de Cuervo por conseguir la adjudicación de la obra fueron en vano, pues esta fue finalmente encargada a José Gabriel González, que cumplió en su propuesta con las exigencias económicas y formales planteadas por el patrono de la fábrica y por la cofradía de la Virgen de Todos los Santos ${ }^{51}$. Fue una decisión tomada, una vez más, en contra del criterio de la Comisión de Arquitectura, que desaprobó en su totalidad el proyecto de González por su "mala forma, peor disposición y desgraciados ornatos" en la junta del 29 de mayo de $1793^{52}$.

La concesión del retablo quedó marcada por el oportunismo de José Gabriel González, quien tras la prohibición de realizar altares de madera y con el objetivo de ser adjudicatario del proyecto se definió el 7 de mayo de 1793 como "profesor del arte de arquitectura y práctico en operaciones y labores de estuco" "53, a pesar de estar documentado como "maestro tallista" desde $1783^{54}$. Las más que probables irregularidades de este cambio de título por parte de González se fundamentan en el resultado del retablo de Omnium Sanctorum, que no correspondía con la técnica constructiva del estuco, según manifestaron Félix Caraza y Fernando Rosales el 15 de febrero de 1798 tras reconocer la obra ${ }^{55}$. Si bien otros retablos ejecutados posteriormente por González - que no fueron enviados a la Academia- sí

y BLANCO MOZO, Juan Luis: "La cultura de Ventura Rodríguez. La biblioteca de su sobrino Manuel Martín Rodriguez", Anuario del Departamento de Historia y Teoría del Arte, 7-8, 1995-1996, pp. 181-221.

49 ARABASF, Libros de actas de las sesiones celebradas por la Comisión/Sección de Arquitectura, leg. 3/139, f. 217r.

${ }^{50}$ Ibidem, f. 219 r.

${ }^{51}$ ROS GONZÁLEZ, Francisco S.: "El retablo mayor de estuco...", op. cit., p. 162.

${ }_{52}$ Ya que el proyecto de González también fue enviado a la Comisión para su evaluación. ARABASF, Libros de actas de las sesiones celebradas por la Comisión/Sección de Arquitectura, leg. 3/139, f. 222v.

${ }^{53}$ ROS GONZÁLEZ, Francisco S.: "El retablo mayor de estuco...”, op. cit., p. 162.

${ }^{54}$ RECIO MIR, Álvaro: "El peso inmenso de la Historia: Neoclasicismo e Historicismo", en HALCÓN, Fátima; HERRERA, Francisco y RECIO, Álvaro: El Retablo Sevillano. Desde sus orígenes a la actualidad. Sevilla, 2009, p. 401.

${ }_{55} \mathrm{Al}$ analizar el retablo de Omnium Sanctorum, Fernando Rosales y Félix Caraza -que sí era práctico en operaciones de estuco- "comprobaron que su estructura interna era de ladrillo entramado en la mayor parte de maderas, sobre la que se había aplicado una especie de encostradura imitando a varias clases de jaspe". ROS GONZÁLEZ, Francisco S.: "La polémica sobre los retablos de estuco en Sevilla a finales del siglo XVIII", Laboratorio de Arte, 14, 2001, pp. 129-130. 
correspondían en parte o en su totalidad con la técnica mencionada ${ }^{56}$, el que nos ocupa, además de no cumplir con la Real Orden de 1791, padeció una notoria fragilidad estructural ${ }^{57}$ debido a las contradicciones del proyecto y a la torpeza de González en el momento de la construcción del retablo. Esta situación ejemplifica el desconocimiento y la escasa influencia de la Academia madrileña sobre las edificaciones sevillanas, causados por la ausencia de académicos en la ciudad que pudieran denunciar las mencionadas ilegalidades ante dicha institución.

Tras el altar mayor de Omnium Sanctorum, la Comisión de Arquitectura evaluó dos proyectos retablísticos más para la ciudad de Sevilla que tampoco fueron llevados a cabo. El primero de ellos corresponde a un altar de estuco destinado a la "Parroquia de San José" e ideado por José Joaquín Troconiz, "discípulo de arquitectura" de la Academia, que fue desaprobado en la junta de la Comisión de Arquitectura celebrada el 16 de septiembre de $1793^{58}$. Los comisionados estimaron otorgar a Troconiz la posibilidad de ejecutar nuevos diseños con "más arreglo de las partes entre sí y mejor elección en el todo", a la que el neófito académico correspondió con la presentación de dos propuestas para la ejecución del retablo de las que se aprobó la primera el 9 de octubre del mismo año ${ }^{59}$. Más allá de las dudas generadas por la denominación del templo al que el retablo debía estar destinado según la Comisión, no consta que el proyecto fuera llevado a cabo, pues ni siquiera el desaparecido retablo que presidía la iglesia del antiguo convento de San José de la Merced Descalza correspondía con los preceptos académicos.

El segundo de los casos y último cronológicamente de cuantos la Academia evaluó para Sevilla antes de 1808, es el concerniente al proyecto presentado por Antonio Aguado para la capilla de la Virgen de los Dolores de la catedral de

${ }^{56}$ Véase otras obras de la producción de González en RECIO MIR, Álvaro: "José Gabriel González, "práctico en obras de estuco», y los retablos neoclásicos de la capilla de Maracaibo de la Catedral de Sevilla", Laboratorio de Arte, 12, 1999, pp. 315-321; ROS GONZÁLEZ, Francisco S.: "La polémica sobre los retablos...”, op. cit., pp. 109-135; RECIO MIR, Álvaro: "José Gabriel González y el camarín neoclásico de la iglesia del Castillo de Aracena", en XVI Jornadas del Patrimonio de la Comarca de la Sierra. La Nava (Huelva). La Nava, 2002, pp. 411-425; y RECIO MIR, Álvaro: "El peso inmenso de la Historia...", op. cit., pp. 400-422.

${ }^{57}$ Retablo que, además de estar conformado por un cuerpo principal comprendido por un camarín central y dos parejas de columnas pareadas a los lados al que se sumaba un ático coronado por un frontón curvo, tenía partes cubiertas de pan de oro. Esto chocaba frontalmente con los ideales académicos. RECIO MIR, Álvaro: "El peso inmenso de la Historia...", op. cit., pp. 401-402.

58 ARABASF, Libros de actas de las sesiones celebradas por la Comisión/Sección de Arquitectura, leg. 3/139, f. 227v.

59 Ibidem, ff. 227v, 234r. 
Sevilla $^{60}$, que fue aprobado por la Comisión de Arquitectura el 28 de febrero de 1805 y ratificado el 30 de marzo del mismo año ${ }^{61}$. Este fue rechazado por el cabildo catedralicio por su excesivo tamaño, reprobación a la que el arquitecto académico respondió pidiendo una planta más exacta de la capilla que la que le fue enviada para acometer el retablo ${ }^{62}$. Finalmente, Aguado concibió unas nuevas trazas que, sin haber pasado el examen de la Comisión de Arquitectura, fueron recibidas por el cabildo en septiembre de 1806, un año después de que el organismo capitular decidiera no acometer la obra por falta de fondos ${ }^{63}$. Los proyectos de Antonio Aguado, discípulo de Juan de Villanueva y director de Arquitectura de la Academia desde el 6 de abril de $1804^{64}$, siguen un modelo novedoso desarrollado por su maestro, que precisamente incluyó en uno de sus diseños un retablo ideado para un crucificado con el mismo esquema compositivo y la misma entrada de luz natural proyectados por Aguado en su primer proyecto ${ }^{65}$. Por otro lado, la segunda propuesta de Aguado guarda una estrecha semejanza con un diseño sin firmar ideado para el ya tratado retablo de la parroquia de Omnium Sanctorum. Esta ligazón podría vincular esta anónima traza con la elaborada por Juan Antonio Cuervo para el citado altar parroquial, dada la afinidad entre este y Aguado ${ }^{66}$, abanderados del nuevo lenguaje arquitectónico academicista. Precisamente, la innovación compositiva de los diseños de Aguado contrasta con la sencillez clasicista del retablo de San José de la propia catedral ${ }^{67}$, levantado en mármol entre

${ }^{60}$ Sobre el mismo véase BAENA GALLÉ, José Manuel y HERNÁNDEZ NÚÑEZ, Juan Carlos: "La Real Academia de San Fernando de Madrid y el Cabildo de la Catedral hispalense: Un proyecto de retablo neoclásico para la capilla de los Dolores", Laboratorio de Arte, 11, 1998, pp. 607-623; y RECIO MIR, Álvaro: "Antonio López Aguado y los proyectos neoclásicos para el retablo de la capilla de los Dolores de la Catedral de Sevilla", Academia, 86, 1998, pp. 379-398.

${ }^{61}$ ARABASF, Libros de actas de las sesiones celebradas por la Comisión/Sección de Arquitectura, leg. 3/139, ff. 391v y 392v.

${ }^{62}$ RECIO MIR, Álvaro: “Antonio López Aguado...”, op. cit., p. 388.

${ }^{63}$ BAENA GALLÉ, José Manuel y HERNÁNDEZ NÚÑEZ, Juan Carlos: "La Real Academia de San Fernando...”, op. cit., p. 611.

${ }^{64}$ Distribución de los premios... 1808, op. cit., p. 78.

${ }^{65}$ Véase el dibujo de Villanueva publicado en SAMBRICIO, Carlos: "El problema del estilo en la Arquitectura madrileña del siglo XVIII. A propósito de una colección de dibujos de Juan de Villanueva”, en SAMBRICIO, Carlos (coord.): Carlos III alcalde de Madrid: 1788-1988. Madrid, 1988, pp. 449-477.

${ }^{66}$ Compruébese la relación formal entre ambas obras consultando simultáneamente FERNÁNDEZ GONZÁLEZ, Alberto: “Trazas y proyectos...”, op. cit., p. 227; y RECIO MIR, Álvaro: "Antonio López Aguado...", op. cit., p. 393.

${ }^{67}$ Sobre el mismo consúltese RECIO MIR, Álvaro: "El retablo de San José y la implantación neoclásica en la Catedral de Sevilla”, Laboratorio de Arte, 11, 1998, pp. 253-273. 
1799 y 1805 según las trazas de Juan Pedro Arnal ${ }^{68}$. Esta disparidad constata la evolución conceptual antes referida, que experimentó la creación arquitectónica academicista a partir de la última década del siglo XVIII, impulsada por relevantes académicos vinculados a Juan de Villanueva ${ }^{69}$. Estos cambios no fueron adoptados por Arnal ${ }^{70}$, director de Arquitectura de la Academia madrileña antes que Aguado, cuyo retablo de San José de la catedral hispalense representa el único hito de la retablística academicista y la única obra de arquitectura -junto al conjunto de la sillería y el órgano de la Capilla Real- concebida según los gustos de la Academia en Sevilla hasta 1808. Se trata de una obra que, precisamente, no fue examinada por la Comisión de Arquitectura.

Fuera del ámbito de la arquitectura de retablos, la Comisión evaluó y rechazó un proyecto de Salvador Tamayo y Rodríguez para la edificación de un nuevo monasterio de la Cartuja de Santa María de las Cuevas de Sevilla en la junta del 28 de septiembre de $1797^{71}$. No obstante, la idea de trasladar el monasterio, motivada por las inundaciones que padecía el mismo, fue retomada con la delineación de nuevos diseños por parte de Felipe Fontana, quien los ideó con el pensamiento de que el nuevo monasterio estuviera ubicado en la "Dehesa de Casaluenga, distante dos leguas de Sevilla", obedeciendo así a las exigencias de la corona ${ }^{72}$. La Comisión, atendiendo a la complejidad del proyecto, rechazó la propuesta de Fontana el 18 de junio de 1799 por la ausencia de solidez, economía, simetría, euritmia y referencias al paraje, a la nivelación del conjunto y a la planificación del abastecimiento de agua para el mismo ${ }^{73}$. Inusualmente, la Comisión dedicó casi dos folios del acta de la citada junta a la resolución del proyecto de Fontana, una circunstancia que únicamente se daba en el caso de que la obra evaluada destacara por su especial urgencia, complejidad e importancia. Por otro lado, y con anterioridad a la citada propuesta, los comisionados académicos también examinaron y desaprobaron el proyecto presentado por Manuel Bernardo Mateo para la edificación de una nueva Casa de la Moneda en la junta celebrada el 26

${ }^{68}$ Según CEÁN BERMÚDEZ, Juan Agustín: Descripción artística de la Catedral de Sevilla. Sevilla, 1804, pp. 82-83.

${ }^{69}$ GARCÍA MELERO, José Enrique: "Los orígenes académicos del romanticismo histórico español: Malestar y crisis en torno a 1792", Espacio, tiempo y forma. Serie VII, Historia del Arte, 5, 1992, pp. 211-262.

${ }^{70}$ Sobre su concepción arquitectónica véase SAMBRICIO, Carlos: "Juan Pedro Arnal, arquitecto del siglo XVIII”, Archivo Español de Arte, 183, 1973, pp. 299-328; y SAMBRICIO, Carlos: "Juan Pedro Arnal y la teoría arquitectónica en la Academia de San Fernando de Madrid”, Goya, 147, 1978, pp. 147-157.

71 ARABASF, Libros de actas de las sesiones celebradas por la Comisión/Sección de Arquitectura, leg. 3/139, f. 294r.

72 Ibidem, f. 309r.

${ }^{73}$ Ibid., f. 309v. 
de mayo de 1792 por carecer de "solidez proporción y buen gusto"74. Los diseños, además de ser denegados, fueron devaluados explícitamente por los comisionados, quienes estimaron que los 78.500 reales de vellón en los que Mateo tasaba este trabajo debían quedar reducidos a la cantidad de 10.200 reales de vellón ${ }^{75}$. Esta situación refleja la continua disputa que Mateo mantenía con la Comisión de Arquitectura ${ }^{76}$, al igual que otros arquitectos del ámbito sevillano vinculados a la Real Escuela de Tres Nobles Artes.

Teniendo en cuenta la animadversión mutua que los arquitectos hispalenses mostraban hacia la Real Academia de San Fernando y las vicisitudes que determinaron la ejecución de los proyectos expuestos a lo largo del presente artículo, correspondería que la finalización del mismo se centrara en tratar las circunstancias que rodearon la edificación de la actual iglesia de San Ildefonso, paradigma culminante de la malograda labor de la Comisión de Arquitectura en la ciudad de Sevilla. Como consecuencia del estado ruinoso de la fábrica primigenia, y descartando la posibilidad de llevar a cabo una simple reforma estructural ya emprendida, el arquitecto local Manuel Núñez ejecutó a comienzos de 1795 varios diseños para edificar la nueva iglesia de San Ildefonso, supuestamente examinados y rechazados por la Real Academia de San Fernando ${ }^{77}$. Curiosamente, el académico Julián de Barcenilla presentó confidencialmente a la Comisión de Arquitectura "tres diseños borradores abreviados" para la construcción "de una iglesia de cuyo título no informaba" evaluados el 28 de agosto por los comisionados académicos, quienes dictaminaron "hacer verbalmente algunas advertencias a Barcenilla sobre el proyecto" por medio del director de arquitectura Francisco Sánchez ${ }^{78}$. Los mencionados bocetos corresponden con la propuesta original que Barcenilla planteó para la iglesia de San Ildefonso de Sevilla, anterior a la ideada por el arquitecto tras aplicar las advertencias prevenidas por Sánchez, cuya ausencia en la junta de la Comisión celebrada el 10 de noviembre de 1795 alentó al resto de comisionados a posponer el veredicto final sobre el proyecto ${ }^{79}$. Esta demora fue denunciada por Barcenilla ante la junta ordinaria de la Real Academia de San Fernando, que el 6 de diciembre del citado año acordó la celebración de un encuentro perentorio entre el autor de los diseños y Francisco Sánchez, a fin

${ }^{74}$ Ibid., f. 193r.

75 Ibid.

${ }^{76}$ Ya se ha señalado el choque conceptual entre Mateo y la Comisión en SAMBRICIO, Carlos: La Arquitectura española..., op. cit., p. 369.

77 A pesar de que no consta su examen en ninguna de las actas de la Academia. La información aparece contenida en OLLERO LOBATO, Francisco: Cultura Artística y Arquitectura..., op. cit., p. 361 .

78 ARABASF, Libros de actas de las sesiones celebradas por la Comisión/Sección de Arquitectura, leg. 3/139, f. 271v.

79 Ibidem, ff. 273v-274r. 
de certificar la aplicación de las correcciones advertidas por este último en el proyecto de Barcenilla y así apresurar la aprobación del mismo ${ }^{80}$. La aquiescencia a la propuesta se manifestó en la reunión de la Comisión de Arquitectura del 20 de febrero de 1796, cuando se insistió en la urgencia de edificar la nueva iglesia de San Ildefonso ${ }^{81}$. Todo este proceso escenifica una vez más la lentitud y las exigencias implícitas en el procedimiento burocrático que debían superar todos los proyectos arquitectónicos presentados a la Comisión, ya fueran enviados por arquitectos ajenos a la Academia o pertenecientes a la misma, lo que perjudicaba a los artífices y a los comitentes de las obras.

La propuesta de Barcenilla fue respaldada por el arzobispado hispalense en el mes de octubre de 1796 y ratificada el 2 de mayo del siguiente año, cuando la citada prelatura autorizó el inicio de las obras y precisó el estricto cumplimiento del citado proyecto académico ${ }^{82}$. No obstante, con anterioridad a la aceptación del proyecto, este fue reconocido por el ya mencionado Manuel Núñez, quien redactó un informe donde se detallaban una serie de deficiencias que el maestro hispalense imputaba al planteamiento de Barcenilla. En primer lugar, Núñez denunció la absoluta semejanza entre los diseños que él envió a Madrid para la construcción del templo que nos ocupa y los ideados posteriormente por Barcenilla, a quien acusaba de pretender diferenciar ambos proyectos mediante la inclusión de una segunda torre en el alzado de la iglesia y de desatender con ello la escasez de caudales para llevar a cabo la obra ${ }^{83}$. Seguidamente, Núñez criticó abiertamente los componentes y los procedimientos propuestos por Barcenilla para la conformación de los cimientos y el levantamiento de los muros de la iglesia, tanto por la inexistencia de algunos de los materiales en las inmediaciones de Sevilla como por el encarecimiento que implicaría su uso en la construcción del templo ${ }^{84}$. Para concluir, Núñez advirtió que Barcenilla, a quien culpaba de no haber tenido en cuenta que el proyecto estaba destinado a Sevilla, carecía de la potestad para nombrar a un maestro concreto que llevara a efecto la obra y que la Academia de San Fernando solo poseía la facultad de corregir los proyectos que se le presentaran, quedando la decisión definitiva sobre los mismos y sus artífices en manos de sus "dueños y administradores" 85 .

${ }^{80}$ ARABASF, Libros de actas de las sesiones particulares, ordinarias, generales, extraordinarias, públicas y solemnes, leg. 3/86, ff. 28v-29r.

81 ARABASF, Libros de actas de las sesiones celebradas por la Comisión/Sección de Arquitectura, leg. 3/139, f. 276r.

${ }^{82}$ OLLERO LOBATO, Francisco: Cultura Artística y Arquitectura..., op. cit., p. 270.

${ }^{83}$ QUILES GARCÍA, Fernando: "Datos para una definición de la arquitectura neoclásica sevillana”, Academia, 84, 1997, p. 317.

${ }^{84}$ OLLERO LOBATO, Francisco: Cultura Artística y Arquitectura ..., op. cit., p. 271.

${ }^{85}$ QUILES GARCÍA, Fernando: "Datos para una definición de la arquitectura...", op. cit., p. 319. 
Las acusaciones manifestadas por Manuel Núñez contra el proyecto ideado por Julián de Barcenilla exponen el afán del maestro sevillano por ser el adjudicatario de la obra. Asimismo, las denuncias de Núñez ejemplifican el rechazo público de los maestros alarifes locales a la actividad realizada por constructores foráneos en la ciudad de Sevilla, a los que consideraban usurpadores de su actividad profesional. Este repudio ya tuvo un antecedente en la "Carta apologética", texto redactado por Lucas Cintora en 1776 como respuesta a la citación enviada por el cabildo catedralicio a maestros no residentes en Sevilla para la reforma de la iglesia del Sagrario, donde su autor criticó la decisión de la institución capitular y la labor posterior de dichos artífices ${ }^{86}$. Si bien el texto de Cintora fue retirado por orden de la Corona en 1779, este indicó la manera de disputar enérgicamente el control de las obras públicas de la ciudad e impugnar públicamente a los arquitectos foráneos que quisieran optar a la concesión de dichos proyectos, que casi en su totalidad fueron pertenecientes a la Real Academia de San Fernando. Aunque se desconoce si el mencionado Lucas Cintora, nombrado académico de mérito por la Real Academia de Bellas Artes de San Carlos de Valencia en $1776^{87}$, repudió públicamente la actividad de los académicos madrileños en Sevilla, son notorias las desavenencias entre este arquitecto y la Comisión de Arquitectura, que rechazó los únicos dos proyectos de Cintora que les fueron presentados ${ }^{88}$. Precisamente, las circunstancias que marcaron la concesión de uno de estos proyectos enviados por Cintora y rechazados por la Comisión, el destinado a la construcción del consistorio de El Castillo de las Guardas, evidencia la disyuntiva entre ambos y la posterior disputa que uno de los arquitectos vinculados a Cintora mantiene frente a la Comisión. La reprobación del proyecto de Cintora para El Castillo de las Guardas en la junta de la Comisión del 23 de agosto de 1786, propició la ejecución de un nuevo plan para la misma obra por parte del arquitecto carmonense José Echamorro, que fue igualmente rechazado el 19 de abril de $1787^{89}$. La decisión de la Comisión, que decidió encargar la obra al académico catalán Ignacio Tomás y aprobar su proyecto el 28 de junio del citado año, no fue aceptada por Echamorro, quien rebatió el proyecto de Tomás ante la Academia madrileña el 27 de marzo de $1788^{90}$. La institución real decidió remitir las reclamaciones de Echamorro a Tomás, quien sorprendentemente aceptó la demanda del arquitecto sevillano ${ }^{91}$, cuya actuación padeció de "cavilosidad, exageración y espíritu de partido" según la Comisión de Arquitectura, que no tuvo más remedio que

${ }^{86}$ FALCÓN MÁRQUEZ, Teodoro: El Sagrario..., op. cit., pp. 78-83.

${ }^{87}$ SAMBRICIO, Carlos: La Arquitectura española..., op. cit., pp. 318-319.

88 Ibidem.

${ }^{89}$ ARABASF, Libros de actas de las sesiones celebradas por la Comisión/Sección de Arquitectura, leg. 3/139, ff. 40v-41r y $57 \mathrm{v}$.

${ }^{90}$ Ibidem, ff. $63 \mathrm{v}$ y $85 \mathrm{v}-86 \mathrm{r}$.

91 Ibid., f. $89 \mathrm{v}$. 
aceptar la adjudicación del proyecto a Echamorro el 29 de mayo de $1788^{92}$. Este ejemplo no solo certifica el escaso interés que algunos académicos mostraban por la concesión de ciertas obras, sino también la obstinada oposición de los constructores sevillanos a las decisiones de la Comisión. El reconocimiento de esta arquitectura por parte de la Real Escuela de Tres Nobles Artes de Sevilla escenificaba la disparidad de criterios entre esta y la Real Academia de San Fernando.

Las circunstancias que marcaron la concesión del proyecto para El Castillo de las Guardas escenifican las desavenencias entre la Academia madrileña y José Echamorro, que fue nombrado responsable de las obras de la iglesia de San Ildefonso de Sevilla el 2 de mayo de $1796^{93}$. Teniendo en cuenta el respaldo que recibió el proyecto de Julián de Barcenilla por parte de la prelatura hispalense tras la aprobación de la Academia, la labor de Echamorro debía consistir en la ejecución del mismo. Sin embargo, Echamorro optó por desacreditar nuevamente la autoridad de la Comisión de Arquitectura, si bien esta vez procedió de forma distinta. Aun sin conocerse los planos trazados por Barcenilla, el aspecto actual de la iglesia difiere en gran medida del lenguaje arquitectónico difundido por la Academia de San Fernando en la última década del siglo XVIII y evidencia el desdén con el que Echamorro afrontó dichos diseños. Cabe destacar que Julián de Barcenilla, nombrado académico de mérito en 1788, teniente director de arquitectura en 1812 y director de la misma rama en $1815^{94}$ por la Academia madrileña, fue uno de los abanderados de la renovación experimentada por la arquitectura academicista en el ocaso del siglo XVIII. De ello se deduce que, a pesar de las expuestas denuncias de Manuel Núñez, el proyecto de Barcenilla variaba sensiblemente de la concepción de Echamorro, cuyas obras quedan definidas por un lenguaje arquitectónico que nunca abandonó la tradición barroca. De modo que la incorporación del almohadillado superpuesto en hiladas verticales -característico de la producción de Echamorro- que acompañan la articulación de las columnas de la portada, el decorativismo del friso y el frontón curvo de esta, la balaustrada convexa del primer cuerpo de las torres, la barroquización de las mismas y la introducción de pilastras cajeadas de orden jónico tanto en el interior como en el exterior del templo, habrían horrorizado a los académicos madrileños, que hubieran pronunciado todo su glosario de críticas hacia la actual iglesia de San Ildefonso. Además de los datos que nos ofrece el análisis de la obra, nos consta por la documentación existente que Echamorro tergiversó los diseños de Barcenilla, dado que, tras la inspección de la obra llevada a cabo por Fernando Rosales en

92 Ibid., f. $91 \mathrm{r}-\mathrm{v}$.

${ }^{93}$ OLLERO LOBATO, Francisco: Cultura Artística y Arquitectura..., op. cit., p. 361.

${ }^{94}$ GARCÍA SEPÚLVEDA, M ${ }^{\mathrm{a}}$ Pilar y NAVARRETE MARTÍNEZ, Esperanza: Real Academia de Bellas Artes de San Fernando: Archivo-Biblioteca. Relación de miembros pertenecientes a la Real Academia de San Fernando (1752-1983, 1984-2006). Madrid, 2007, p. 61. 
febrero de 1804, este advirtió que Echamorro no construyó la iglesia "con arreglo a lo mandado en los diseños" 95 . Sin embargo, el arquitecto de Carmona, que no pretendió ejercer en esta ocasión una oposición conspicua a la Comisión de Arquitectura, eludió la decisión de esta y del arzobispado de Sevilla en un ejercicio taimado de rebeldía frente a los preceptos academicistas, demostrando así otra forma de impugnar las decisiones tomadas en la Academia. Se trata de una actitud de desobediencia hacia la Comisión de Arquitectura ampliamente difundida en el municipio hispalense por arquitectos y comitentes que propició una conflictiva relación entre dicho organismo y la ciudad, ejemplificada en los diferentes casos que se han desarrollado y analizado en este artículo.

Fecha de recepción: 24 de septiembre de 2017

Fecha de aceptación: 12 de abril de 2018

${ }^{95}$ OLLERO LOBATO, Francisco: Cultura Artística y Arquitectura..., op. cit., p. 363. 